\title{
News from Generative Artificial Intelligence is Believed Less
}

\author{
Chiara Longoni ${ }^{*}$, Andrey Fradkin ${ }^{1}$, Luca Cian $^{2}$, Gordon Pennycook $^{3}$ \\ ${ }^{1}$ Questrom School of Business, Boston University, Boston, MA 02215, USA \\ ${ }^{2}$ Darden School of Business, University of Virginia, Charlottesville, VA 22903, USA \\ ${ }^{3}$ Hill/Levene Schools of Business, University of Regina, Regina, SK S4S 0A2, Canada \\ *clongoni@bu.edu
}

Please cite as: Longoni, C., Fradkin, A., Cian, L., \& Pennycook, G. (2021). News from Generative Artificial Intelligence is Believed Less. Working paper available at https://psyarxiv.com/wgy9e

Datasets, preregistrations, and all experimental materials are available on the Open Science Framework at https://bit.ly/2YVyh8z. 


\begin{abstract}
Artificial Intelligence (AI) can generate text virtually indistinguishable from text written by humans. A key question, then, is whether people believe news generated by AI as much as news generated by humans. AI is viewed as lacking human motives and emotions, suggesting that people might view news written by AI as more accurate. By contrast, two pre-registered experiments on representative U.S. samples $(N=4,034)$ showed that people rated news written by AI as less accurate than news written by humans. People were more likely to incorrectly rate news written by AI (vs. a human) as inaccurate when it was actually true, and more likely to correctly rate it as inaccurate when it was indeed false. Our findings are important given the increasing adoption of $\mathrm{AI}$ in news generation, and the associated ethical and governance pressures to disclose it use and address standards of transparency and accountability.
\end{abstract}

Keywords: artificial intelligence, algorithms, news, accuracy, transparency, trust 


\section{GENERATIVE AI NEWS}

One of the applications of Artificial Intelligence (AI) that has shown the most promising advances in the last decade is that of generative AI: AI algorithms capable of producing textual, visual, and auditory content with little no human intervention. To illustrate, in 2020 the Generative Pre-trained Transformer 3 (GPT-3) has been lauded as the most advanced neural network capable of producing text - a fictional story, a poem, an answer to a math problem, or even a programming code_-virtually indistinguishable from text written by a person (Brown et al., 2020; Kobis \& Mossink 2021; Kreps et al., 2020).

Applications of generative AI are more pervasive than one might think. For instance, leading media companies such as the Associated Press, Forbes, the New York Times, the Washington Post, and ProPublica, use AI to generate entire articles from scratch and automatically report on crimes, financial markets, politics, sporting events and foreign affairs (Dörr, 2015; Marconi, 2020). Generative AI is also increasingly used as an input in the writing process across several domains_-from user- and company-generated content, to institutional communications from public organizations and governments ${ }^{1}$.

When AI is used to generate content, its role is typically not disclosed. In news articles, for example, the byline is rarely attributed to an AI algorithm even when an algorithm was used. Without this disclosure, readers cannot determine whether an AI was used from the text alone (Brown et al., 2020; Köbis \& Mossink 2021; Kreps et al., 2020). However, given the potential misuse or unintended consequences of this new technology (Abid, Farooqi, \& Zou, 2021; Köbis, Bonnefon, \& Rahwan, 2021), ethicists and policymakers have argued that the use of AI should be disclosed (Dörr, 2015; Montal \& Reich, 2017). Indeed, it's possible that such disclosure will

\footnotetext{
${ }^{1}$ For example, https://perma.cc/4VBZ-H5JC and copy.ai contain a list of applications of the open-source GPT-3 to generate novels, essays, titles and headlines, podcast notes, resumes, recipes, computer codes, company statements, websites, advertisements, etc.
} 


\section{GENERATIVE AI NEWS}

be mandated by law (Walch 2020), as advocated, for instance, in the Algorithmic Justice and Online Platform Transparency Act of 2021.

How will people perceive news generated by AI once it's labeled as such? At the moment, we do not know the answer to this question. Existing research in the area of generative AI has either focused on the technical aspects of text generation (e.g., Brown et al., 2020; Kreps et al., 2020) or on the risks and benefits of AI to publishers (e.g., Marconi 2020), thereby neglecting to consider how people will perceive news from AI (Guzman, 2019). News perceptions play a critical role for the civil society, as trustworthy news reporting can provide a check on misconduct and corruption (OECD, 2018) and influence important societal outcomes, from elections to finance, public policy, and political economy (Greifeneder et al., 2020, Lazer et al., 2018). It is therefore both timely and important to understand how people will perceive news generated by AI, which is the focus of the present research.

\section{Generative AI and Perceptions of News Accuracy}

We focus on a specific dimension of news perception: that of accuracy- judgments of the veracity of a news item. Accuracy is an important dimension of news perception because the extent to which a news item is initially accepted as true determines the extent to which that item is processed and later remembered (Ecker et al., 2010; Koriat et al., 2000), and the extent to which it will influence subsequent judgments (Kruglanski, 1989) even in the face of retractions and corrections (Ayers \& Reader, 1998; Lewandowsky et al., 2012). As such, accuracy perceptions have received considerable attention in the literature (Pennycook \& Rand, 2021).

There are two opposing theoretical perspectives related to the perceived accuracy of AIgenerated news. The first predicts that news from AI would be perceived as more accurate than news from human reporters. AI is typically viewed as lacking human desires, agenda, motives, 


\section{GENERATIVE AI NEWS}

and emotions (Gray et al., 2007; Gray \& Wegner, 2012; Weisman et al., 2017). These qualities might be incorporated into how people judge content generated by AI — as being relayed impartially and dispassionately or, in other words, as more truthful. Furthermore, people appreciate algorithms more than humans for tasks that are impersonal (Berger et al. 2021), require objectivity (Castelo, Bos, \& Lehmann, 2019) or impartiality (Jago \& Laurin 2021). As people want journalism to be impartial and neutral (American Press Institute, 2018), this $A I$ appreciation account predicts that people would perceive news from AI as more accurate than news from human reporters, with higher trust ascribed to AI than human reporters.

The alternative account is grounded in people's resistance toward replacement of humans by automated systems (Dawes, 1979; Grove \& Meehl, 1996; Meehl, 1954). This line of research has shown that people are averse to AI supplanting humans, on the grounds that AI is unable to adapt to mutable, unpredictable, or unique contexts (Dietvorst \& Bharti, 2020; Dietvorst, Simmons, \& Massey, 2015; Longoni, Bonezzi \& Morewedge, 2019; 2020), that it lacks empathy and experiential abilities (Castelo et al., 2019; Longoni \& Cian, 2020), and threatens symbolic consumption (Granulo, Fuchs, \& Puntoni, 2020). Moreover, news production might be considered a morally laden task, and people view it inappropriate for AI to make moral decisions (Bigman \& Gray, 2018). Thus, the competing AI aversion account predicts that people would perceive news from AI as less accurate than news from human reporters, with lower trust ascribed to AI than human reporters.

\section{Experiments $1 \& 2$}

\section{Method}

We tested these competing predictions in two large experiments on samples recruited on the platform Lucid, which use quota sampling to provide respondents representative of the U.S. 


\section{GENERATIVE AI NEWS}

population on age, gender, ethnicity and geographic region. Experiment 1 employed a betweensubject/separate evaluation paradigm: participants saw either news items tagged as written by an AI or by a human. Experiment 2 employed a within-subject/joint evaluation paradigm: participants saw both news items tagged as written by AI and by a human. We conducted the within-subject experiment to refine the measurement of accuracy, as the evaluability of the writer should be more salient in a joint paradigm (Hsee et al., 1999). Our main dependent variable was perception of news accuracy, and our secondary dependent variable was trust toward the reporter.

Datasets, preregistrations of sample sizes, dependent variables, and primary analyses, and all experimental materials are available on the Open Science Framework at https://bit.ly/2YVyh8z.

\section{Participants}

The preregistered samples were 3,000 participants for Experiment 1 and 1,000 for Experiment 2, recruited on the platform Lucid. In total, we recruited 3,029 participants $(1,469$ female, 1,560 male) in Experiment 1, and 1,005 (490 female, 515 male) in Experiment 2.

\section{Design}

\section{Experiment 1}

In a 2-cell, between-subject design and across three experimental waves, participants were randomly assigned to a condition in which they saw news items tagged as written by an AI reporter or a condition in which they saw news items tagged as written by a human reporter.

\section{Experiment 2}

In a 2-cell, within-subject design, participants saw both news items tagged as written by an $\mathrm{AI}$ and by a human reporter. 
GENERATIVE AI NEWS

\section{Materials}

All news items comprised a text headline and an accompanying photo. We used real news headlines and real photos that appeared in news outlets at the time of the experiment. We focused on headlines rather than full articles because news consumption largely occurs at the level of headlines, as is often the case on social media (Gottfried \& Shearer, 2016). We omitted information about the outlet given research indicating that publisher information has no effect on accuracy perceptions (Dias, Pennycook, \& Rand 2020; Pennycook et al., 2018). To assess whether the effect of AI disclosure was moderated by the news' actual veracity (whether the news was objectively accurate or inaccurate), we predetermined whether each news item was true or false by relying on the fact-checking site Snopes.com (see Pennycook et al., 2020 for further on this approach). As it was important to compare subjective ratings of accuracy (a continuous measure of accuracy and our dependent variable) with an objective measure of accuracy (a binary measure of veracity), we did not consider news that Snopes.com had rated as “mostly false," “mostly true," “mixture," "unproven," “miscaptioned," or “misattributed.” We report in Table 1 each news headline by experiment, experimental wave, and date of factchecking.

\section{*Insert Table 1 about here*}

In Experiment 1, participants saw a total of 30 news items in wave one (15 true news; 15 false news); a total of 36 news items in wave two (15 true news from wave one, plus 3 novel true news; 15 false news from wave one, plus 3 novel true news); and a total of 42 news items in wave three (15 true news from wave one, plus 3 true news from wave two, plus 3 novel true news; 15 false news from wave one, plus 3 false news from wave two, plus 3 novel false news). We leveraged the three waves to add novel news to account for the potential effect of the "age" 


\section{GENERATIVE AI NEWS}

of the news - the amount of time a certain news had been accessible to the public — as novelty affects reactivity to news (Vosoughi et al. 2018). In Experiment 2, participants saw a total of 20 news (10 true; 10 false). Stimuli are available at https://bit.ly/2YVyh8z.

\section{Procedure}

Participants read that they would be presented with news headlines that had appeared on various outlets and social media platforms, and that these headlines may had been written by human reporters or by artificial intelligence (AI) reporters. We described AI reporters as "algorithmic processes that convert data into narrative news texts with limited to no human intervention beyond the initial programming choices" (Carlson, 2015). To rule out the potential role of believing that AI reporters had differential access to sources or were differentially skilled at data mining, we clarified that "human or AI reporters wrote these news headlines based on information available to them and to the news outlets employing them at the time in which the news headline was written."

Participants were then randomly assigned to one of two conditions as per the respective experimental design (between-subject in Experiment 1, and within-subject in Experiment 2). Then, participants viewed the news items one at a time and in random order. Our pre-registered and primary dependent variable was news accuracy, measured after each news item as follows: "To the best of your knowledge, how accurate is this news headline?" 1 - Not at all accurate, 4 Very accurate (Pennycook et al., 2018). Our pre-registered and secondary dependent variable was trust toward the reporter, measured at the end of the survey with two items: "To what extent do you trust [a human reporter/ an AI reporter] to write accurate news headlines?" (1 - Do not trust at all, 5 - Trust completely), "To what extent do you think [a human reporter/ an AI reporter] is capable of writing accurate news headlines?" (1 - Not at all, 5 - Very much). 


\section{GENERATIVE AI NEWS}

As pre-registered, we also collected the following measures as prior research indicated their relevance for news discernment: risk appraisals, information seeking behavior, political orientation, religiosity, and demographic variables. We report in the Supplementary Appendix the details of the measurements of these variables as well as the specific rationales for collecting them. Although included in the pre-registration, we made no a-priori hypotheses with respect to the potential interactions of these measures with the independent variable, and therefore acknowledge the exploratory nature of the respective analyses, which we also report in the Supplementary Appendix.

At the end of the survey, and in line with prior research (Pennycook et al., 2018), participants were asked ( $i$ ) if they had searched for any of the headlines while responding to the survey, and (ii) if they had responded randomly at any point. A manipulation check in Experiment 1 assessed whether participants correctly recalled that the headlines they had viewed had been generated by a human or an AI reporter. Upon completion of the survey, participants could follow a link to know which of the news items were true and which were false.

\section{Results}

As pre-registered, we performed the main analyses at the level of individual accuracy perceptions ratings (i.e., one data point per news item per participant) using a linear regression with robust standard errors clustered on participant.

\section{Experiment 1}

\section{Perceived Accuracy}

A linear regression with robust standard errors clustered on participant on the individual accuracy perceptions ratings (i.e., one data point per news item per participant) revealed that tagging news items as written by an AI was associated with an average reduction in perceived 


\title{
GENERATIVE AI NEWS
}

accuracy of 7.6pp (SE 1.5pp, $p<.001)$ compared to the control condition, in which news items were tagged as written by a human (Column 1; Table 2). Regression specifications with news item fixed-effects, which allowed for baseline accuracy rating to vary with the news (Column 2), and separately for true (Column 3) and false news (Column 4), yielded the same conclusions. The effect was directionally larger for false news than true news, but the two effects are not statistically different $(p=.359)$. The negative effect of AI disclosure emerged for 41 out of the 42 news items tested, and ranged from $-20 \mathrm{pp}$ to $3 \mathrm{pp}$ across news. Thus, these results strongly supported aversion toward algorithmic reporting. These results are shown in Table 2 and Figure 1.

\author{
*Insert Table 2 about here* \\ *Insert Figure 1 about here*
}

\section{Trust}

A t-test on the average of the two items measuring trust $(r=.635, p<.001)$ revealed that participants trusted AI reporters less than human reporters $\left(M_{\mathrm{AI}}=2.57, S D=0.90 ; M_{\mathrm{Human}}=3.30\right.$, $S D=0.97 ; t(3016.7)=21.51, p<.001)$, again supporting aversion toward algorithmic reporting.

\section{Mediation}

To further probe aversion toward algorithmic reporting, we explored whether trust mediated the effect of reporter on perceived accuracy. To do so, we averaged all of the responses for each participant, and then conducted a mediation using linear models for the mediation and outcome equations (1,000 simulations; Mediation Package for R; Tingley, Yamamoto, Hirose, Keele, \& Imai, 2014, Taylor \& Noseworthy, 2020). Note that this analysis requires the assumption of sequential ignorability, which is quite stringent and implies that there are no unmodeled variables that affect both the trust and accuracy. 
GENERATIVE AI NEWS

The effect of reporter (human vs. AI) on trust was significant $(\beta=-.73, p<.001, \mathrm{CI}$ : [$.80,-0.67]$ ), and trust (specifically, $\alpha^{*}$ reporter $+\beta^{*}$ trust $+\varepsilon$ ) had a significant effect on perceived accuracy $(\beta=.169, p=<.001, \mathrm{CI}:[.155, .183])$. The indirect effect of reporter on perceived accuracy through trust was significant $(\beta=-.12, p=<.001, \mathrm{CI}:[-.14,-.11])$. These results further corroborated aversion toward AI reporting.

\title{
Experiment 2
}

\section{Perceived Accuracy}

A linear regression with robust standard errors clustered on participant on the individual accuracy perceptions ratings (i.e., one data point per news item per participant) revealed that tagging news items as written by AI was associated with an average reduction in perceived accuracy of $14.5 \mathrm{pp}(S E 1.5 \mathrm{pp}, p<.001)$ compared to the control (Column 1, Table 3). A regression specification with news item fixed-effects, which allowed for the baseline response to vary with the news item (Column 2), and separately for true (Column 3) and false news (Column 4) yielded the same results. The negative effect of AI disclosure emerged for all news items, ranging from -24 to -7. Overall, Experiment 2 replicated Experiment 1 and pointed to an even larger effect, again supporting aversion towards algorithmic reporting. The results are shown in Table 3 and Figure 2.

\author{
*Insert Table 3 about here* \\ *Insert Figure 2 about here*
}

\section{Trust}

A t-test on the average of the two items measuring trust $(r=.607, p<.001)$ revealed that participants trusted AI reporters less than human reporters $\left(M_{\mathrm{AI}}=2.75, S D=.89 ; M_{\mathrm{Human}}=3.39\right.$, $S D=1.00 ; t(1975.6)=15.19, p<.001)$, again supporting aversion toward algorithmic reporting. 
GENERATIVE AI NEWS

\section{Mediation}

To account for the fact that participants were treated for some news items and not others (i.e., viewed some news items tagged as written by an AI reporter but not others), we used a multi-level mediation model to analyze Experiment 2. Specifically, we modeled both the mediation and outcome equations as mixed models with participant random effects $(1,000$ simulations; Mediation Package for R; Tingley, Yamamoto, Hirose, Keele, \& Imai, 2014, Taylor $\&$ Noseworthy, 2020). The effect of reporter (human vs. AI) on trust was significant $(\beta=-.64, p$ $<.001, \mathrm{CI}:[-0.66,-0.63])$, and trust had a significant effect on perceived accuracy $(\beta=.14, p$ $<.001$, CI: $[.12, .16])$. The indirect effect of the reporter on perceived accuracy through trust was significant $(\beta=-.09, p<.001, \mathrm{CI}:[-.10,-.08])$. These results replicated those of Experiment 1 and corroborated aversion to algorithmic reporting.

\section{General Discussion}

Across two large pre-registered experiments on representative U.S. samples, we examined how disclosing use of AI in news generation affected news accuracy perceptions. The results strongly corroborated the AI aversion account: disclosing the use of AI led people to believe the news substantially less, a negative effect explained by lower trust toward AI reporters. The effect was robust to experimental paradigm (separate and joint evaluations), respondents' characteristics (risk appraisals, information seeking behavior, political orientation, religiosity, and demographics), and emerged for every single news item that we included (with one exception in Experiment 1), indicating robustness across actual news veracity and age/novelty.

This research makes two theoretical contributions. First, it builds on and extends the literature on psychological responses to automated systems and on human-machine interaction 


\section{GENERATIVE AI NEWS}

(Dawes, 1979; Grove \& Meehl, 1996; Meehl, 1954), indicating new - and perhaps surprising depths to this AI aversion given that past scholarship has shown cases of both AI appreciation (Berger et al., 2021; Castelo, Bos, \& Lehman, 2019; Logg et al., 2019; Longoni \& Cian, 2020) and aversion (e.g., Cadario, Longoni, \& Morewedge 2021; Dietvorst \& Bharti, 2020; Dietvorst, Simmons \& Massey, 2015; Longoni, Bonezzi, \& Morewedge, 2019). Though this literature spans over decades, it has mostly focused on outcome variables such as stated or reveal preference. Our research is the first to empirically examine the effect of disclosing use of generative AI on accuracy perceptions in a context of everyday importance. Even though the effect we document falls in the domain of news accuracy, the robustness of the negative effect of AI implies that it is likely to generalize to the many other domains in which AI systems are increasingly used to generate text—-from social media posts, podcast notes, to institutional communications from corporations and governments.

We make a second theoretical contribution to research on perceptions of news accuracy (Ecker et al., 2010; Koriat et al., 2000) by documenting a negative effect of AI disclosure on news perceptions. This effect is novel, as research on generative AI has largely focused on technical improvements and people's ability to discriminate between human and AI-generated text (Brown et al., 2020; Kobis \& Mossink 2021; Kreps et al., 2020). Thus, people's perceptions of the output of generative AI have largely been neglected. Shifting the perspective from the technical aspects of text production to the public is paramount. Adoption of generative AI is likely to further accelerate and become an industry norm in the coming years due to its many advantages - efficiencies in coverage, speed, and costs, and tremendous leaps in the capability to generate text indistinguishable from text generated by humans. As adoption of AI widens, however, so will the pressure from governance bodies to disclose its use and address standards of 


\section{GENERATIVE AI NEWS}

transparency and accountability (Dörr, 2015; Montal \& Reich, 2017), and to remedy the potential for bias and misuse (Abid, Farooqi, \& Zou, 2021; Köbis, Bonnefon, \& Rahwan, 2021).

Examining how the public will respond to disclosure of use of generative AI is thus a somewhat neglected priority (Guzman, 2019). Our results point to a potentially detrimental consequence of disclosing use of generative AI, which may further exacerbate the already declining public trust in news outlets (Flesher, 2019; Cian, Longoni \& Krishna 2020).

Our research has limitations that offer several opportunities for future research. First, future research could map out the theoretical boundaries of aversion to algorithmic reporting. Even though our results point to trust as mediating variable, we acknowledge the limitations of this approach and refrain from making strong causal claims. Future research could build on our findings both by testing alternative psychological processes leading to a negative AI effect, and by exploring whether there are circumstances where the effect reverses, with people appreciating (rather than derogating) AI reporters. For instance, recent research has shown that threat of inequality in medical outcomes or hiring decisions increases preference for algorithms (Bigman et al., 2021; Jago \& Laurin 2021).

A second set of limitations pertains to the stimuli we employed in our experiments. We focused on news related to the COVID-19 pandemic. Future research could systematically examine whether relying on AI to generate text may be associated with higher (rather than lower) accuracy perceptions and overall evaluation as a function on the type of domain. For instance, it is possible that generative AI could have a positive effect in domains characterized by high consequentiality for the self (e.g., frivolous versus consequential) and base-rate uncertainty (e.g., well-known versus unknown). 
GENERATIVE AI NEWS

Another limitation is that we tested news headlines rather than whole articles. We made this choice based on considerations pertaining to both external and construct validity. In terms of external validity, we used headlines because the public largely consumes news at the level of story headline (Shearer \& Matsa, 2018). In terms of construct validity, it is unclear how people would assess the accuracy of an article comprising several statements, each statement potentially varying in perceived accuracy (e.g., it is unclear whether people would average the perceived accuracy of each statement, or weigh the perceived accuracy of the first statement more, etc.). As our key variable was accuracy perceptions, we decided to assess perceptions of accuracy of one statement (i.e., a headline), which we could predetermine to be objectively entirely true or entirely false. Even though this approach has been adopted by other research on accuracy judgments (Pennycook \& Rand 2021), future research could investigate the effect of AI disclosure on perceptions of accuracy of full articles or text.

Overall, this research is only the first step toward understanding the complex phenomenon of how people perceive generative AI. Given the speed with which AI systems are being developed and adopted, we hope this research will spur further investigation of this important topic. 
GENERATIVE AI NEWS

Table 1

News headline by experiment, experimental wave, and date of fact-checking

\begin{tabular}{|c|c|c|c|}
\hline $\begin{array}{l}\text { Code } \\
\text { name }\end{array}$ & Headline & $\begin{array}{l}\text { Date it appeared } \\
\text { on Snopes.com }\end{array}$ & Experiment \\
\hline \multicolumn{4}{|c|}{ TRUE NEWS } \\
\hline $\mathrm{T} 1$ & $\begin{array}{l}\text { Ivanka Trump Holds Variety of Trademarks in China, Including One For } \\
\text { Coffins }\end{array}$ & 14 April 2020 & Experiment 1 (wave 1)) \\
\hline $\mathrm{T} 2$ & Obama Urged US Pandemic Preparedness in 2014 & 13 April 2020 & Experiment 1 (wave 1) \\
\hline $\mathrm{T} 3$ & Trump Praises China for Its 'Transparency’ on COVID-19 & 16 April 2020 & Experiment 1 (wave 1) \\
\hline $\mathrm{T} 4$ & $\begin{array}{l}\text { Experts and Officials Warned in } 2018 \text { US Couldn't Respond Effectively to a } \\
\text { Pandemic }\end{array}$ & 1 April 2020 & Experiment 1 (wave 1) \\
\hline $5 \mathrm{~T}$ & $\begin{array}{l}\text { Trump Administration Sends } 18 \text { Tons of Personal Protective Equipment to } \\
\text { China in Early } 2020\end{array}$ & 31 March 2020 & Experiment 1 (wave 1) \\
\hline $6 \mathrm{~T}$ & Las Vegas Homeless Sleep in 'Social Distanced' Parking Lot & 31 March 2020 & Experiment 1 (wave 1) \\
\hline $7 \mathrm{~T}$ & Empire State Building Displays 'Siren' Lights During COVID-19 Pandemic & 31 March 2020 & Experiment 1 (wave 1) \\
\hline $8 \mathrm{~T}$ & Amazon Solicits Donations to Help Pay Worker Sick Leave & 25 March 2020 & Experiment 1 (wave 1) \\
\hline 9T & $\begin{array}{l}\text { World Wrestling Entertainment CEO Vince McMahon Advises Trump on } \\
\text { Reopening the U.S. economy }\end{array}$ & 16 April 2020 & $\begin{array}{l}\text { Experiment } 1 \text { (wave 1) } \\
\text { Experiment } 2\end{array}$ \\
\hline $10 \mathrm{~T}$ & Trump Golfs And Holds Rallies After Learning About COVID-19 Threat & 1April 2020 & $\begin{array}{l}\text { Experiment } 1 \text { (wave 1) } \\
\text { Experiment } 2\end{array}$ \\
\hline $11 \mathrm{~T}$ & Cities Closed Schools and Businesses During the 1918 Pandemic & 31 March 2020 & $\begin{array}{l}\text { Experiment } 1 \text { (wave 1) } \\
\text { Experiment } 2\end{array}$ \\
\hline $12 \mathrm{~T}$ & Trump's Name To Appear on COVID-19 Stimulus Checks & 15 April 2020 & $\begin{array}{l}\text { Experiment } 1 \text { (wave 1) } \\
\text { Experiment } 2\end{array}$ \\
\hline $13 \mathrm{~T}$ & Mass Graves Dug in New York's Hart Island For COVID-19 Deaths & 10 April 2020 & $\begin{array}{l}\text { Experiment } 1 \text { (wave 1) } \\
\text { Experiment } 2\end{array}$ \\
\hline $14 \mathrm{~T}$ & CBS News Use Footage from Italy for New York COVID-19 Report & 9 April 2020 & $\begin{array}{l}\text { Experiment } 1 \text { (wave 1) } \\
\text { Experiment } 2\end{array}$ \\
\hline $15 \mathrm{~T}$ & Time Magazine Warned About Global Warming and Pandemic Years Ago & 9 April 2020 & $\begin{array}{l}\text { Experiment } 1 \text { (wave 1) } \\
\text { Experiment } 2\end{array}$ \\
\hline $16 \mathrm{~T}$ & Ohio Man Who Called COVID-19 a 'Political Ploy' Dies from the Disease & 22 April 2020 & $\begin{array}{l}\text { Experiment } 1 \text { (wave 1) } \\
\text { Experiment } 2\end{array}$ \\
\hline $17 \mathrm{~T}$ & Photo Shows Flyer for an 'End the Lockdown' Rally & 22 April 2020 & $\begin{array}{l}\text { Experiment } 1 \text { (wave 1) } \\
\text { Experiment } 2\end{array}$ \\
\hline $18 \mathrm{~T}$ & Trump Suggests Injecting Disinfectants as COVID-19 Treatment & 24 April 2020 & Experiment 1 (wave 2) \\
\hline $19 \mathrm{~T}$ & President Trump Tweets That Reporters Should Return 'Noble' Prizes & 27 April 2020 & $\begin{array}{l}\text { Experiment } 1 \text { (wave 2) } \\
\text { Experiment } 2\end{array}$ \\
\hline $20 \mathrm{~T}$ & $\begin{array}{l}2008 \text { Nobel Prize Winner Luc Montagnier Said That COVID-19 Coronavirus } \\
\text { Disease Was Artificially Created in a Lab }\end{array}$ & 29 April 2020 & $\begin{array}{l}\text { Experiment } 1 \text { (wave 3) } \\
\text { Experiment } 2\end{array}$ \\
\hline $21 \mathrm{~T}$ & Trump Blames Obama for 'Bad' COVID-19 Tests & 1 May 2020 & $\begin{array}{l}\text { Experiment } 1 \text { (wave } 3) \\
\text { Experiment } 2\end{array}$ \\
\hline \multicolumn{4}{|c|}{ FALSE NEWS } \\
\hline $1 \mathrm{~F}$ & Michigan's Governor Bans Sale of American Flags, Plants, Seeds & 13 April 2020 & Experiment 1 (wave 1) \\
\hline $2 \mathrm{~F}$ & Experts Recommend to Sanitize Fabric Masks in a Microwave & 10 April 2020 & Experiment 1 (wave 1) \\
\hline $3 \mathrm{~F}$ & Seven Children Die in Senegal from COVID-19 Vaccine & 10 April 2020 & Experiment 1 (wave 1) \\
\hline $4 \mathrm{~F}$ & Himalayas Visible from Northern India for First Time in 30 Years & 9 April 2020 & Experiment 1 (wave 1) \\
\hline $5 \mathrm{~F}$ & Bill Gates Sued by India Over Vaccination Deaths & 10 April 2020 & Experiment 1 (wave 1) \\
\hline $6 \mathrm{~F}$ & Kenyan Government Has Maasai Tribe Whip People To Enforce Curfew & 7 April 2020 & Experiment 1 (wave 1)) \\
\hline $7 \mathrm{~F}$ & Plagues Repeated Exactly Every 100 Years & 7 April 2020 & Experiment 1 (wave 1) \\
\hline
\end{tabular}


GENERATIVE AI NEWS

\begin{tabular}{|c|c|c|c|}
\hline $8 \mathrm{~F}$ & Uninsured Teen Die of COVID-19 After Being Denied Treatment & 3 April 2020 & Experiment 1 (wave 1) \\
\hline $9 \mathrm{~F}$ & Ventilators Found 'Stashed' in a Warehouse in New York & 31 March 2020 & Experiment 1 (wave 1) \\
\hline $10 \mathrm{~F}$ & $\begin{array}{l}\text { Financier George Soros Owns Lab in China Where COVID-19 Was } \\
\text { "Developed." }\end{array}$ & 2 April 2020 & Experiment 1 (wave 1) \\
\hline $11 \mathrm{~F}$ & Your Coronavirus Stimulus Check Counts Against Your 2020 Tax Refund & 7 April 2020 & Experiment 1 (wave 1)) \\
\hline $12 \mathrm{~F}$ & $\begin{array}{l}\text { Trump Tweets in } 2009 \text { That He Would 'Never Let Thousands of Americans } \\
\text { Die From a Pandemic' }\end{array}$ & 17 April 2020 & Experiment 1 (wave 1) \\
\hline $13 \mathrm{~F}$ & News Media Fake Photos of Jacksonville Beaches & 20 April 2020 & Experiment 1 (wave 1) \\
\hline $14 \mathrm{~F}$ & CDC Guidelines for Reporting COVID-19 Deaths Artificially Inflate Numbers & 20 April 2020 & $\begin{array}{l}\text { Experiment } 1 \text { (wave 1) } \\
\text { Experiment } 2\end{array}$ \\
\hline $15 \mathrm{~F}$ & The House Gives Itself a \$25M Raise in Coronavirus Aid Bill & 31 March 2020 & $\begin{array}{l}\text { Experiment } 1 \text { (wave 1) } \\
\text { Experiment } 2\end{array}$ \\
\hline $16 \mathrm{~F}$ & $\begin{array}{l}\text { Bill Gates and the ID2020 Coalition Are Using COVID-19 To Build Global } \\
\text { Surveillance State }\end{array}$ & 22 April 2020 & $\begin{array}{l}\text { Experiment } 1 \text { (wave 1) } \\
\text { Experiment } 2\end{array}$ \\
\hline $17 \mathrm{~F}$ & Nancy Pelosi Visited Wuhan in November 2019 & 26 April 2020 & $\begin{array}{l}\text { Experiment } 1 \text { (wave 2) } \\
\text { Experiment } 2\end{array}$ \\
\hline $18 \mathrm{~F}$ & Photo Shows Signs Carried by COVID-19 Anti-Lockdown Protesters & 23 April 2020 & $\begin{array}{l}\text { Experiment } 1 \text { (wave 2) } \\
\text { Experiment } 2\end{array}$ \\
\hline $19 \mathrm{~F}$ & Nobel Laureate Tasuku Honjo Says COVID-19 Was 'Man-Made' & 27 April 2020 & $\begin{array}{l}\text { Experiment } 1 \text { (wave 3) } \\
\text { Experiment } 2\end{array}$ \\
\hline $20 \mathrm{~F}$ & $\begin{array}{l}\text { Elisa Granato, One of the UK's First Covid-19 Vaccine Trial Participants, Has } \\
\text { Died }\end{array}$ & 27 April 2020 & $\begin{array}{l}\text { Experiment } 1 \text { (wave } 3) \\
\text { Experiment } 2\end{array}$ \\
\hline $21 \mathrm{~F}$ & 1866 Court Case Bar States from Enforcing Social-Distancing Regulations & 27 April 2020 & $\begin{array}{l}\text { Experiment } 1 \text { (wave 3) } \\
\text { Experiment } 2\end{array}$ \\
\hline $22 \mathrm{~F}$ & CDC Readjusted the COVID-19 Death Toll From 60,000 Down to 37,000 & & Experiment 2 \\
\hline $23 \mathrm{~F}$ & Churches in Kansas City Required to Record List of Attendees & & Experiment 2 \\
\hline
\end{tabular}




\section{GENERATIVE AI NEWS}

\section{Table 2}

Results of Experiment 1: Negative effect of AI disclosure on perceptions of news accuracy by regression specification

\begin{tabular}{rcccc}
\hline \hline & \multicolumn{4}{c}{ Perceptions of News Accuracy } \\
\hline & $(1)$ & $(2)$ & $(3)$ & $(4)$ \\
\hline AI reporter & $-0.076^{* * *}$ & $-0.076^{* * *}$ & $-0.068^{* * *}$ & $-0.085^{* * *}$ \\
condition & $(0.015)$ & $(0.015)$ & $(0.018)$ & $(0.017)$ \\
\hline$M$ & 2.56 & 2.56 & 2.72 & 2.41 \\
$S D$ & 1.04 & 1.04 & 1.03 & 1.02 \\
Sample & All & All & True News & False News \\
Item FE & No & Yes & Yes & Yes \\
Observations & 109,068 & 109,068 & 54,534 & 54,534 \\
Adjusted $R^{2}$ & 0.001 & 0.093 & 0.059 & 0.085 \\
\hline \hline
\end{tabular}

Table 2 displays the effect of AI disclosure (vs. human/control) on perceptions of news accuracy in Experiment 1 using linear regressions. Each observation is one participant by news item. All standard errors, reported in parentheses, are clustered by participant. Column 1 presents the baseline regression. Column 2 includes fixed effects (FE) for individual news items. Columns 3 and 4 present the treatment effects for news items that are either true (3) or false (4). These results are based on the entire dataset: we did not remove responses by those who (i) reported searching on Google (15\% of the sample), (ii) reported responding randomly 22\% of the sample), or (iii) failed the manipulation check (i.e., if they incorrectly recalled whether the reporter was AI or human; $18 \%$ of the sample). Statistical conclusions do not change if we restrict analysis to those who did not search on Google, did not respond randomly, or passed the manipulation check. 
GENERATIVE AI NEWS

Table 3

Results of Experiment 2: Negative Effect of AI disclosure on perceptions of news accuracy by regression specification

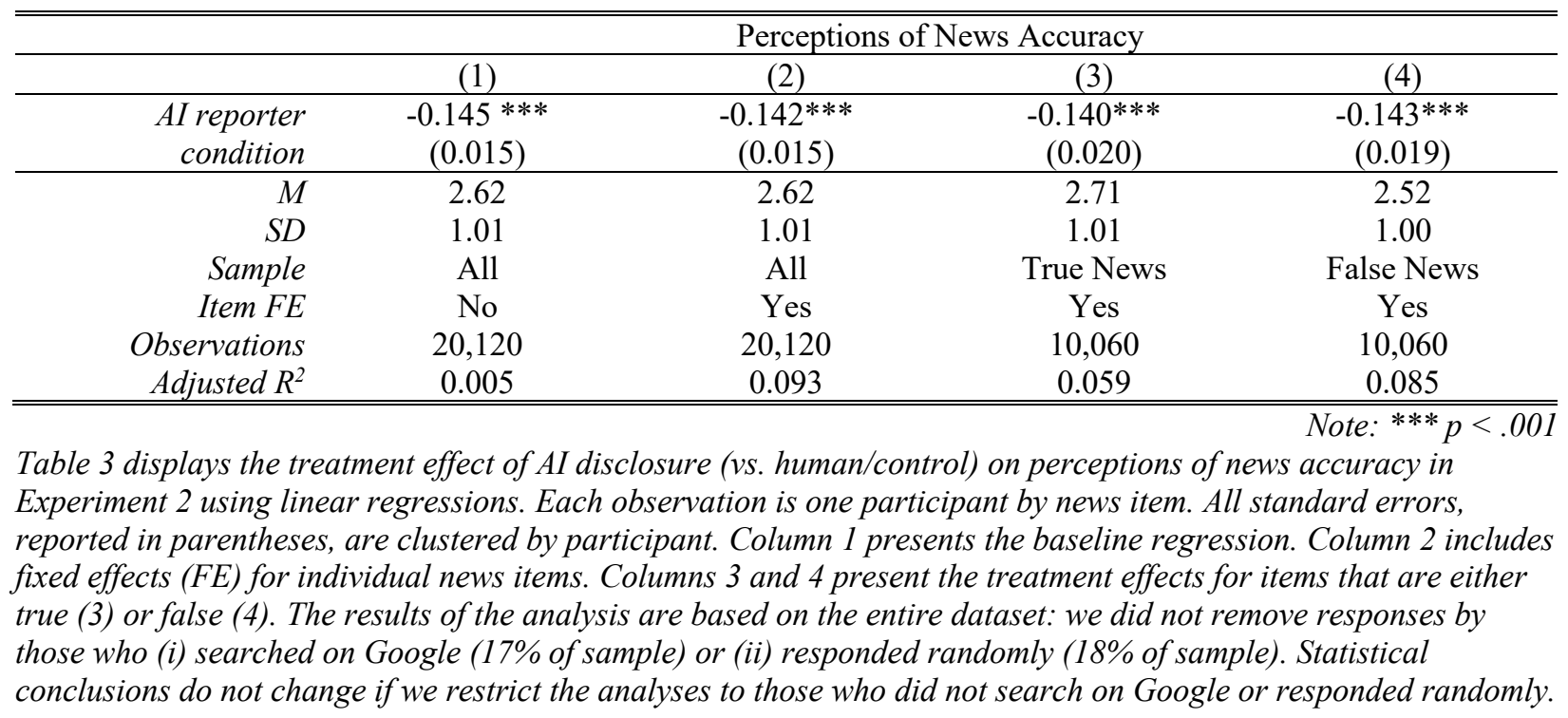


Figure 1

Results of Experiment 1: Negative effect of AI disclosure on perceptions of news accuracy by news item

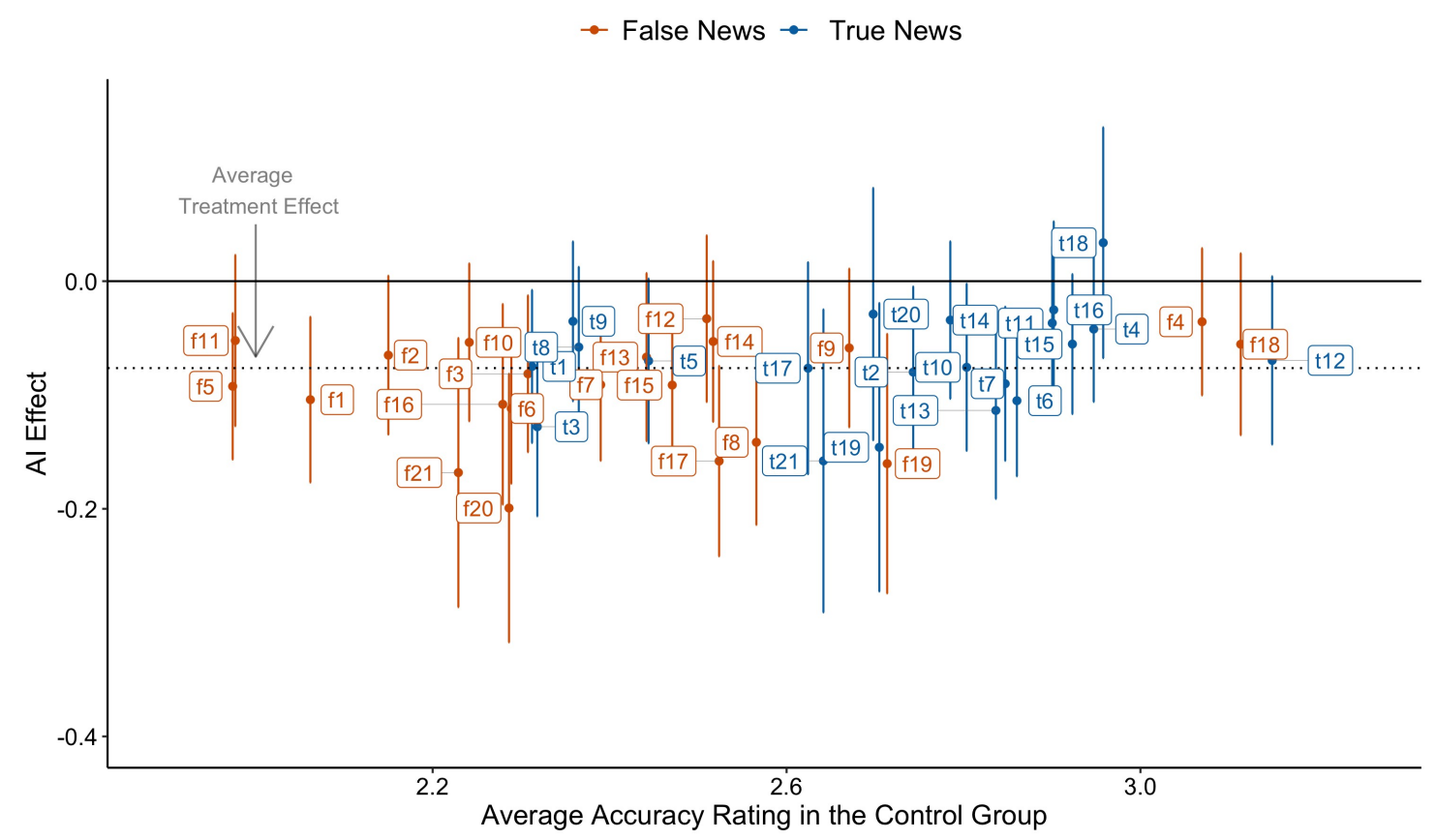

Figure 1 displays estimates of the effect of AI disclosure (vs. human/control) on perceived news accuracy, and the 95\% confidence interval for regressions conducted for each news item in Experiment 1. Point estimates and confidence intervals are computed based on separate regressions run for each news item. The dotted line plots the average treatment effect for the entire sample. 


\section{GENERATIVE AI NEWS}

Figure 2

Results of Experiment 2: Negative effect of AI disclosure on perceptions of news accuracy by news item

$\rightarrow$ False News $\rightarrow$ True News

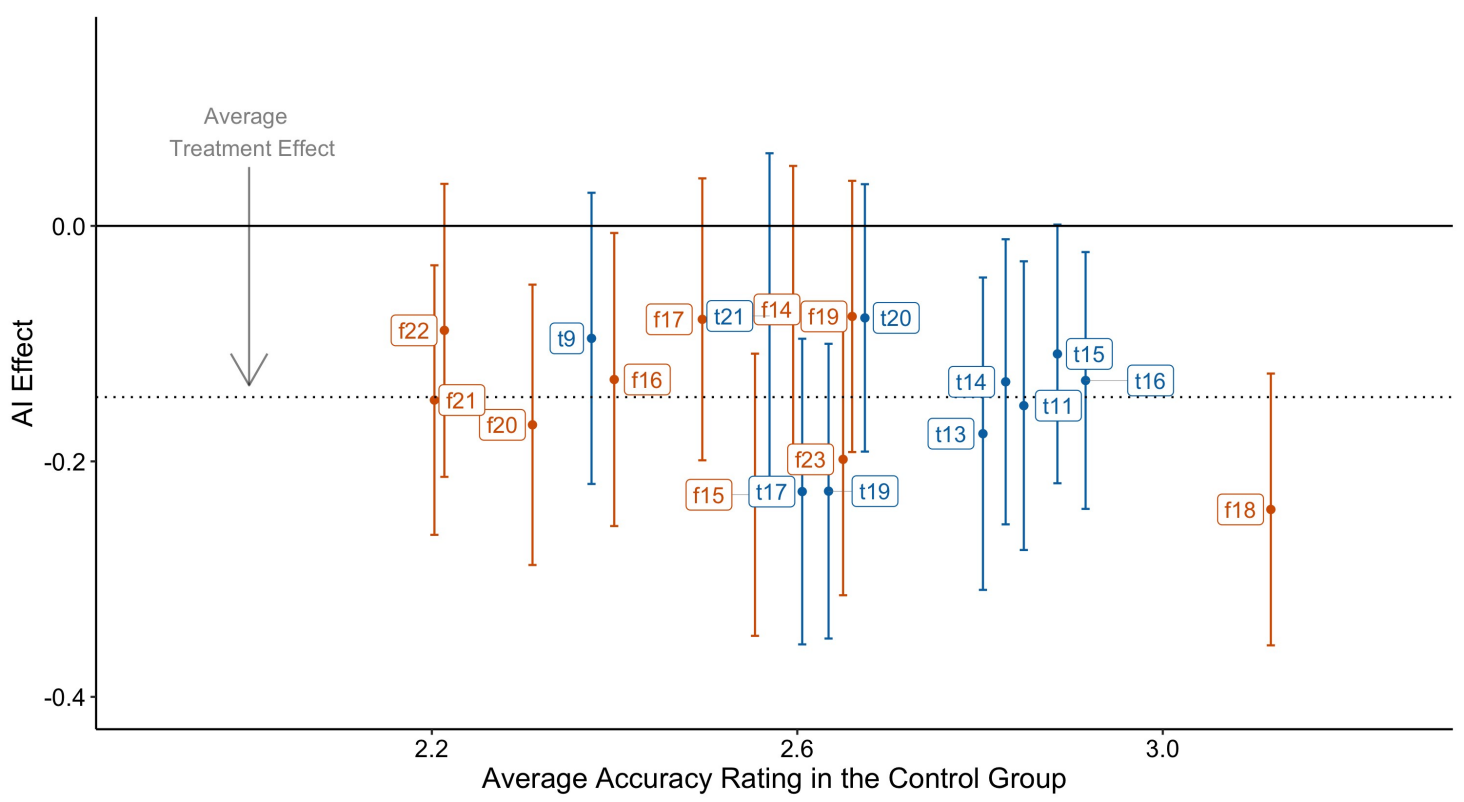

Figure 2 displays estimates of the effect of AI disclosure (vs. human/ control) on perceived news accuracy, and the 95\% confidence intervals for regressions conducted for each news item in Experiment 2. Point estimates and confidence intervals are computed based on separate regressions run for each news item. The dotted line plots the average treatment effect for the entire sample. 


\section{References}

Abid, A., Farooqi, M, \& Zou, J. (2021). Large language models associate Muslims with violence. Nature Machine Intelligence, 3, 461-463.

American Press Institute (2018). What the public expects from the press (and what journalists think). https://bit.ly/3xjH9nx

Berger, B., Adam, M., Rühr, A., \& Benlian, A. (2021). Watch me improve-Algorithm aversion and demonstrating the ability to learn. Business and Information Systems Engineering, 63(1), 55-68.

Bigman, Y. E., \& Gray, K. (2018) People are averse to machines making moral decisions. Cognition, 181, 21-34.

Brenan, M. (2020). Americans remain distrustful of mass media. Gallup. https://bit.ly/3dk2F54

Brown, T. B., Mann, B., Ryder, N., Subbiah, M., Kaplan, J., Dhariwal, P., Neelakantan, A., Shyam, P., Sastry, G., Askell, A., et al. (2020) Language models are few-shot learners https://bit.ly/3quesRV (2020).

Cadario, R., Longoni, C., \& Morewedge, C. K. (2021). Understanding, explaining, and utilizing medical artificial intelligence, Nature Human Behavior, 5, 1636-42.

Carlson, M. (2015). The robotic reporter: automated journalism and the redefinition of labor, compositional forms, and journalistic authority. Digital Journalism, 3(3), 416-31.

Castelo, N., Bos, M. V., \& Lehman, D. (2019). Task-dependent algorithm aversion, Journal of Marketing Research, 56(5), 809-25.

Cian, L., Longoni, C., \& Krishna, A. (2020). Advertising a desired change: When process simulation fosters (vs. hinders) credibility and persuasion. Journal of Marketing Research, 57(3), 489-508.

Dawes, R. M. (1979). The robust beauty of improper linear models in decision making. American Psychologist, 34(7), 571-82.

Dias, N., Pennycook, G. \& Rand, D. G. (2020). Emphasizing publishers does not effectively reduce susceptibility to misinformation on social media. The Harvard Kennedy School Misinformation Review. https://bit.ly/3gLVq66

Dietvorst, B. J., \& Bharti, S. (2020). People reject algorithms in uncertain decision domains because they have diminishing sensitivity to forecasting error. Psychological science, 31(10), 1302-1314.

Dietvorst, B. J., Simmons, J. P., \& Massey, C. (2015). Algorithm aversion: People erroneously avoid algorithms after seeing them err. Journal of Experimental Psychology: General, 
$144,114-26$.

Dörr, K. (2015) Mapping the field of algorithmic journalism. Digital Journalism, 4, 700-722.

Ecker, U., Lewandowsky, S., \& Tang, D. T. (2010). Explicit warnings reduce but do not eliminate the continued influence of misinformation. Memory \& Cognition, 38,10871100 .

Flesher, V. (2019). The fall, rise, and fall of media trust. Columbia Journalism Review, https://bit.ly/30NpqHb

Gottfried, J., \& Shearer, E. (2016). News use across social media platforms. Pew Research Center. https://pewrsr.ch/3bdnBrA

Gray, H. M., Gray, K., \& Wegner, D. M. (2007). Dimensions of min perception. Science. 315, 619.

Gray, K., \& Wegner, D. M. (2012). Feeling robots and human zombies: Mind perception and the uncanny valley. Cognition, 125, 125-130.

Greifeneder, R., Jaffé, M., Newman, E.J., \& Schwarz, N. (Eds.) The psychology of fake news: Accepting, sharing, and correcting misinformation. London, UK: Routledge. (2020).

Grove, W. M., \& Meehl, P. E. (1996). Comparative efficiency of informal (subjective, impressionistic) and formal (mechanical, algorithmic) prediction procedures: The clinical-statistical controversy. Psychology, Public Policy, and Law, 2, 293-323.

Guzman, A. (2019). Prioritizing the audience's view of automation in journalism Digital Journalism, 7(8), 1185-1190.

Hsee, C. K., Blount, S., Loewenstein, G. F., \& Bazerman, M. H.(1999). Preference reversals between joint and separate evaluations of outcomes. Psychological Bulletin, 125, 576-90.

Jago, A. S., \& Laurin, K. (2021). Assumptions about algorithms' capacity for discrimination. Personality and Social Psychology Bulletin, 1-14.

Köbis, N., Bonnefon, J., \& Rahwan, I. (2021). Bad machines corrupt good morals. Nature Human Behavior, 5, 679-685.

Köbis, N. \& Mossink, L. D. (2021). Artificial intelligence versus Maya Angelou: Experimental evidence that people cannot differentiate AI-generated from human-written poetry. Computers in Human Behavior, 114.

Koriat, A., Goldsmith, M., \& Pansky, A. (2000). Toward a psychology of memory accuracy. Annual Review of Psychology, 51, 481-537.

Kreps, S. E., McCain, M., \& Brundage, M. (2020). All the news that's fit to fabricate: AIgenerated text as a tool of media misinformation. https://bit.ly/3dhDyj4 


\section{GENERATIVE AI NEWS}

Kruglanski, A.W. (1989). The psychology of being 'right': On the problem of accuracy in social perception and cognition. Psychological Bulletin, 106(3), 395-409.

Lazer, D. M., Baum, M. A., Benkler, Y., Berinsky, A. J., Greenhill, K. M., Menczer, F., Metzger, M. J., Nyhan, B., Pennycook, G., Rothschild, D., et al. (2018). The science of fake news. Science, 359(6380), 1094-1096.

Lewandowsky, S., Ukh, E., Seifert, C. M., Schwarz, N., \& Cook, J. (2012). Misinformation and its correction: Continued influence and successful debiasing. Psychological Science in the Public Interest, 13(3), 106-131.

Logg, J. M., Minson, J., \& Moore, D. A. (2019). Algorithm appreciation: People prefer algorithmic to human judgment Organizational Behavior and Human Decision Processes, 151, 90-103.

Longoni, C., Bonezzi, A., \& Morewedge, C. K. (2019). Resistance to medical artificial intelligence. Journal of Consumer Research, 46(4), 629-650.

Longoni, C., Bonezzi, A., \& Morewedge, C. K (2020) Resistance to medical artificial intelligence is an attribute in a compensatory decision process: response to Pezzo and Beckstead (2020), Judgment and Decision Making, 15 (3), 446-448.

Longoni, C. \& Cian, L. (2020) Artificial intelligence in utilitarian vs. hedonic contexts: The "word-of-machine" effect" Journal of Marketing, 86 (1), 91-108.

Marconi, F. (2020). Newsmakers: Artificial Intelligence and the Future of Journalism, Columbia University Press.

Meehl, P. (1954). Clinical versus statistical prediction: a theoretical analysis and review of the literature Minneapolis, MN: University of Minnesota Press

Park, S., Fisher, C., Flew, T., \& Dulleck, U. (2020). Global mistrust in news: The impact of social media on trust. International Journal on Media Management, 22(2), 83-96.

OECD (Organisation for Economic Cooperation and Development) (2018) The role of media and investigative journalism in combating corruption. https://bit.ly/3qCWVH6

Park, S., Fisher, C., Flew, T., \& Dulleck, U. (2020). Global mistrust in news: The impact of social media on trust. International Journal on Media Management, 22(2), 83-96.

Peiser, J. (2019). The rise of the robot reporter. The New York Times. https://nyti.ms/3u3dr5o

Pennycook, G., Binnendyk, J., Newton, C., \& Rand, D. G. A practical guide to doing behavioral research on fake and misinformation. https://psyarxiv.com/g69ha

Pennycook, G., Cannon, T. D., \& Rand, D. G. (2018). Prior exposure increases perceived accuracy of fake news. Journal of Experimental Psychology: General, 147(12),18651880 . 


\section{GENERATIVE AI NEWS}

Pennycook, G., McPhetres. J., Zhang, Y., Lu, J. G., \& Rand, D. G. (2020). Fighting covid-19 misinformation on social media: Experimental evidence for a scalable accuracy-nudge intervention. Psychological Science, 31,770- 780.

Pennycook, G., \& Rand, D. G. (2021). The psychology of fake news. Trends in Cognitive Sciences.

Ritter, Z. (2018). How much does the world trust journalists? Gallup, https://bit.ly/3diqtGd

Shearer, E., \& Matsa, K. E. (2018). News use across social media platforms. https://pewrsr.ch/3pq0oHK

Taylor, N., \& Noseworthy, T. J. (2020). Compensating for innovation: Extreme product incongruity encourages consumers to affirm unrelated consumption schemas. Journal of Consumer Psychology, 30, 77- 95.

Tingley, D., Yamamoto, T., Hirose, K., Keele, L., \& Imai, K. (2014). Mediation: R package for causal mediation analysis. Journal of Statistical Software, 59(5), 1-38.

Vosoughi, S. Roy, D., \& Aral, S. (2018). The spread of true and false news online. Science $359(6380), 1146-1151$.

Walch, K. (2021). AI Laws are coming. Forbes, https://bit.ly/2ULDVf6 
GENERATIVE AI NEWS

\section{Author Contributions}

C.L., A.F. and L.C. designed research; C.L. and L.C. performed research; A.F. analyzed data; and C.L., A.F., L.C. and G.P. wrote the paper.

\section{Competing interests}

The authors declare no competing interests. 